\title{
DEPARTMENT OF VETERANS AFFAIRS AMPUTATION SYSTEM OF CARE: 5 YEARS OF ACCOMPLISHMENTS AND OUTCOMES
}

\author{
Joseph B. Webster, MD; Cindy E. Poorman, MSPT; David X. Cifu, MD
}

\section{INTRODUCTION}

or more than 150 years, the Department of Veterans Affairs (VA) has held the care provided to Veterans with limb amputations as a high priority. To many Americans, the Veteran with an amputation epitomizes the sacrifices made on our nation's behalf. The VA is dedicated to providing optimal care for these individuals in order to restore function and improve quality of life. This commitment has been reaffirmed over time through the passage of key legislation such as the Veterans Medical Programs Amendments of 1992 and the Veterans Health Care Eligibility Act of 1996 [1]. The life-changing effect of amputation on Veterans has also been acknowledged through the VA's long-standing commitment to amputation prevention programs [2].

In 2008, after years of planning and preparation, VA approved and began implementing the Amputation System of Care (ASoC) in order to enhance the quality and consistency of care provided to the Veteran with limb loss. In 2010 , Dr. Sigford described this paradigm shift in VA amputation care and the implementation plan for the ASoC [3]. The driving force behind this program was the need to provide lifelong care for servicemembers with combat-related amputations from the military conflicts in Iraq and Afghanistan and for Veterans with amputations from diseases such as diabetes and peripheral vascular disease. The system is designed to provide the latest practices in medical care, prosthetic technology, and rehabilitation management in order to assist individuals with amputations in reaching their highest level of functional independence. In this article, we highlight the accomplishments and outcomes of the ASoC in the domains of program scope, organizational structure, clinical services, and additional performance metrics $5 \mathrm{yr}$ after initial program implementation.

\section{PROGRAM SCOPE, ORGANIZATIONAL STRUCTURE, AND EVOLUTION}

The ASoC is an integrated, national healthcare delivery system. It provides patient-centered, gender-sensitive, age-appropriate, life- long, holistic care and care coordination for Veterans with limb amputations. Through the provision of quality rehabilitation and prosthetic care, the ASoC minimizes disability and enables the highest level of social, vocational, and recreational reintegration. The ASoC provides specialized expertise in amputation care through incorporating the latest practices in medical rehabilitation, therapy services, and prosthetic technology. This specialized expertise is provided in an interdisciplinary format lead by physician medical directors. Amputation rehabilitation coordinators assure coordination of services and provider communication both across the continuum of care and across facilities. These factors, along with specialized education and training, have enhanced the environment of care and created greater consistency in the delivery of rehabilitation services for Veterans with amputations. Achieving these goals provides the VA the opportunity to fulfill its vision to be a world leader in providing lifelong amputation care.

The ASoC operates in close collaboration with the Department of Defense (DOD) amputation care programs. While the VA system of care has many features similar to the DOD amputation care programs, it also differs in several ways. Both the VA and DOD amputation care programs use a team approach to care and focus on individual treatment goals, can provide any prosthetic device that is commercially available, and are involved in collaborative research involving new prosthetic technology and treatment advances. The two systems differ in that the DOD specialized amputation care is focused primarily at three Advanced Rehabilitation Centers, whereas the VA system is more diffuse, using a tiered approach with services spread across 133 
medical facilities. The DOD amputation care programs are focused primarily on providing initial prosthetic fitting and acute rehabilitation, whereas the VA system places a greater emphasis on lifelong care and care management. The population of individuals served in the two programs differs in that the DOD system primarily provides care for Active Duty servicemembers with amputations resulting from trauma. Only a relatively small percent of the Veteran population with amputations has an amputation of traumatic etiology, with the majority of amputations being the result of disease processes. Importantly, however, while each program has unique characteristics, steps have been taken to ensure that care across the systems is well coordinated in order to provide optimal care from the time of injury through the entire lifespan and achieve the best possible outcomes.

From an administrative and leadership standpoint, the ASoC is organized under Rehabilitation and Prosthetics Services and within the Physical Medicine and Rehabilitation (PM\&R) program. The leadership for the program is provided by a national medical director and national program manager. In many respects, the ASoC has been modeled after the VA's Polytrauma System of Care, which was implemented in 2005. The Polytrauma System of Care and the ASoC work in close collaboration on many aspects of program development and clinical care.

The ASoC clinical services are organized into four distinct components of care: Regional Amputation Centers (RACs), Polytrauma Amputation Network Sites (PANSs), Amputation Clinic Teams (ACTs), and Amputation Points of Contact in order to provide graded levels of clinical expertise and accessibility to care. Each VA medical facility across the nation is classified into one of these four designations. The RAC and PANS locations are designed to provide the highest level of clinical expertise in amputation care, including medical care, surgical services, specialized rehabilitation programs, and orthotic and prosthetic laboratories for the fabrication and fitting of artificial limbs. The RAC and PANS facilities have been strategically selected to also provide appropriate geographic distribution across the United States. While VA funds all aspects of amputation care, Figure 1 lists the four components of care

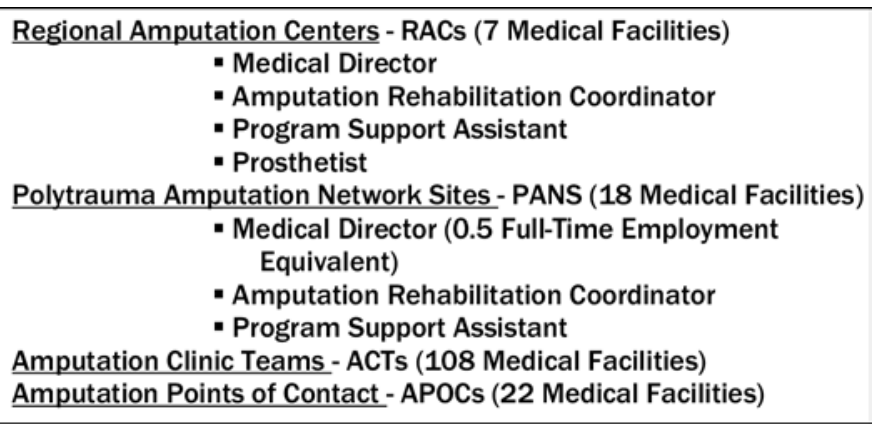

\section{Figure 1.}

Amputation System of Care Department of Veterans Affairs medical facility designations and Amputation System of Care personnel at Regional Amputation Centers and Polytrauma Amputation Network Sites.

and shows the personnel categories that receive additional, targeted ASoC funding [1].

Since initiation of the program, the VA has dedicated significant resources to expand the capacity of the system and the availability of specialized amputation care expertise. The ASoC has accomplished this partly through enhancing facility infrastructure and providing funding support for specialized equipment in the areas of rehabilitation therapies, artificial limb fabrication, and telehealth services. In fiscal year 2009, $\$ 4.8$ million was spent on building enhancements, rehabilitation equipment, and prosthetic laboratory equipment. In fiscal year 2010, \$1.2 million was dedicated to providing telehealth equipment across multiple facilities. In fiscal year 2011, an additional $\$ 785,000$ was expended on telehealth equipment, rehabilitation therapy equipment, and prosthetic laboratory equipment. In fiscal year 2012, \$1.0 million was dedicated to equipment in order to support the expanded number of ACT sites.

Since 2008, the ASoC has also expanded the number and type of personnel supported by the program, as well as increasing the level of services offered at various medical facilities in order to meet the needs of Veterans. While the number of RAC sites has remained stable at 7 , in 2013 , the ASoC increased the number of PANS facilities from 15 to 18 with the addition of PANS designations in San Diego, San Antonio, and Salt Lake City. The ASoC also increased the number of ACT locations within the ASoC from 101 to 108 with the growth of amputation care providers and expansion of services at these facilities. With expansion of the number of PANS locations and the addition of 
both PANS medical directors and regional prosthetist positions to the ASoC, the total number of personnel with dedicated funding support from the system of care has grown from 51 in 2008 to 82 in 2013 (61\% increase).

\section{CLINICAL SERVICES AND ENHANCEMENTS}

\section{Population Served}

The ASoC serves Veterans and servicemembers with amputations that result from any etiology. The ASoC also provides services to Veterans who have undergone limb salvage procedures and those who have a high likelihood of requiring a limb amputation in the near future, secondary to either disease or injury. The majority of Veterans with amputation have required an amputation because of vascular diseases such as diabetes or peripheral vascular disease. Amputations caused by disease processes generally occur in the aging Veteran and are associated with numerous comorbidities, such as cardiovascular disease, hypertension, end-stage renal disease, and arthritis. Veterans with amputations because of trauma, including combat-related injuries, are predominantly younger and typically require a longer continuum of care in the VA system. This is true for Veterans of Operation Enduring Freedom (OEF), Operation Iraqi Freedom (OIF), and Operation New Dawn (OND), as well as cohorts of Veterans with combat-related injuries and amputations from prior conflicts including World War II and the Vietnam era. Both the dysvascular and traumatic amputation groups require high-quality, specialized, lifelong care.

Despite advances in medical care and an emphasis on prevention programs, studies have shown an increase in the overall prevalence of amputations secondary to vascular diseases and have predicted a doubling of the elderly amputation population by 2030 [4-5]. The care for this population has been predicted to require significant resources [4]. Significant growth has also been seen in the total population of Veterans with amputations being seen at VA facilities annually since 2000 [6]. This increase has been relatively steady over the past $13 \mathrm{yr}$, with approximately 25,000 Veterans with amputations being seen in VA facilities in 2000 compared with more than 80,000 being seen for services in 2013. There continues to be a significant number of new amputations performed in the VA each year, with an average of 7,669 new amputation procedures performed annually in the VA between 2008 and 2013. Taking into account all levels of amputation, approximately 21 percent of these amputations involve the upper limb and 79 percent involve the lower limb [6]. These trends emphasize the need for maintaining a comprehensive system of care for Veterans with amputations.

\section{Amputation Specialty Outpatient Clinic Volumes and Access}

With progressive implementation of the ASoC, along with growth in the Veteran population with amputations, the ASoC amputation specialty interdisciplinary team outpatient clinic volumes have steadily grown. Figure 2 demonstrates this growth, with unique individual patient visits increasing from 11,762 to 14,865 (26\%) over the $5 \mathrm{yr}$ period between 2008 and 2013, for an average annual growth rate of 5.2 percent. The total number of amputee clinic encounters increased even more dramatically: $\mathbf{4 8}$ percent growth over the $5 \mathrm{yr}$ period for an annual growth rate of 9.6 percent. This is likely the result of improved follow-up care for specific rehabilitation and prosthetic limb issues, as well as enhanced capture of Veterans returning to clinic for routine annual follow-up visits.

As noted, one of the primary objectives of the ASoC is to have the capability to provide lifelong care to servicemembers and Veterans with trauma-related amputations from the military conflicts OIF/OEF/OND that transition their care to the VA at military separation. A report from the VA Office of the Inspector General found that within $5 \mathrm{yr}$ of military separation, 99 percent of servicemembers with combat-related amputations had transitioned their care to the VA [7]. One aspect of this capability is assuring that there is adequate access to the amputation specialty clinic and providers. Figure 3 displays the substantial growth that has been seen in this population being served in the outpatient amputee specialty clinics since 2008 . Over the past $5 \mathrm{yr}$, the annual growth rate for this specific population has been 62 percent per year for unique individual patients and 78 percent per year for total clinic encounters.

An important performance metric for the amputation specialty clinics is timely access for this increasing population. In order to meet the demand of the everincreasing patient volume, the ASoC clinic sites have expanded the number and capacity of their clinics in order to maintain appropriate and timely clinic access. The ability of the ASoC to meet this growth in demand 


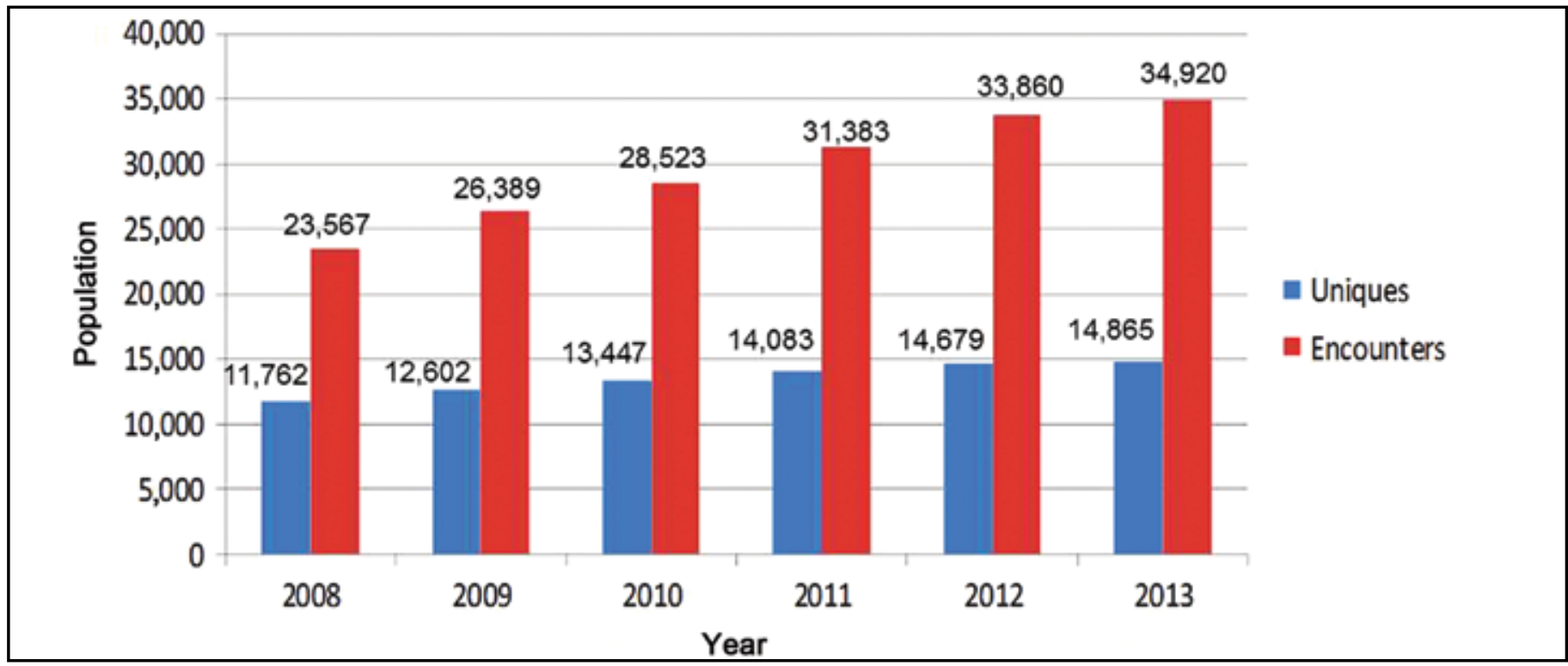

Figure 2.

Outpatient amputee specialty clinic volumes (2008 to 2013). Total amputee population. Figure shows total number of unique Veterans with amputations seen in Department of Veterans Affairs amputation specialty clinics as well as total number of clinic encounters for years 2008 to 2013.

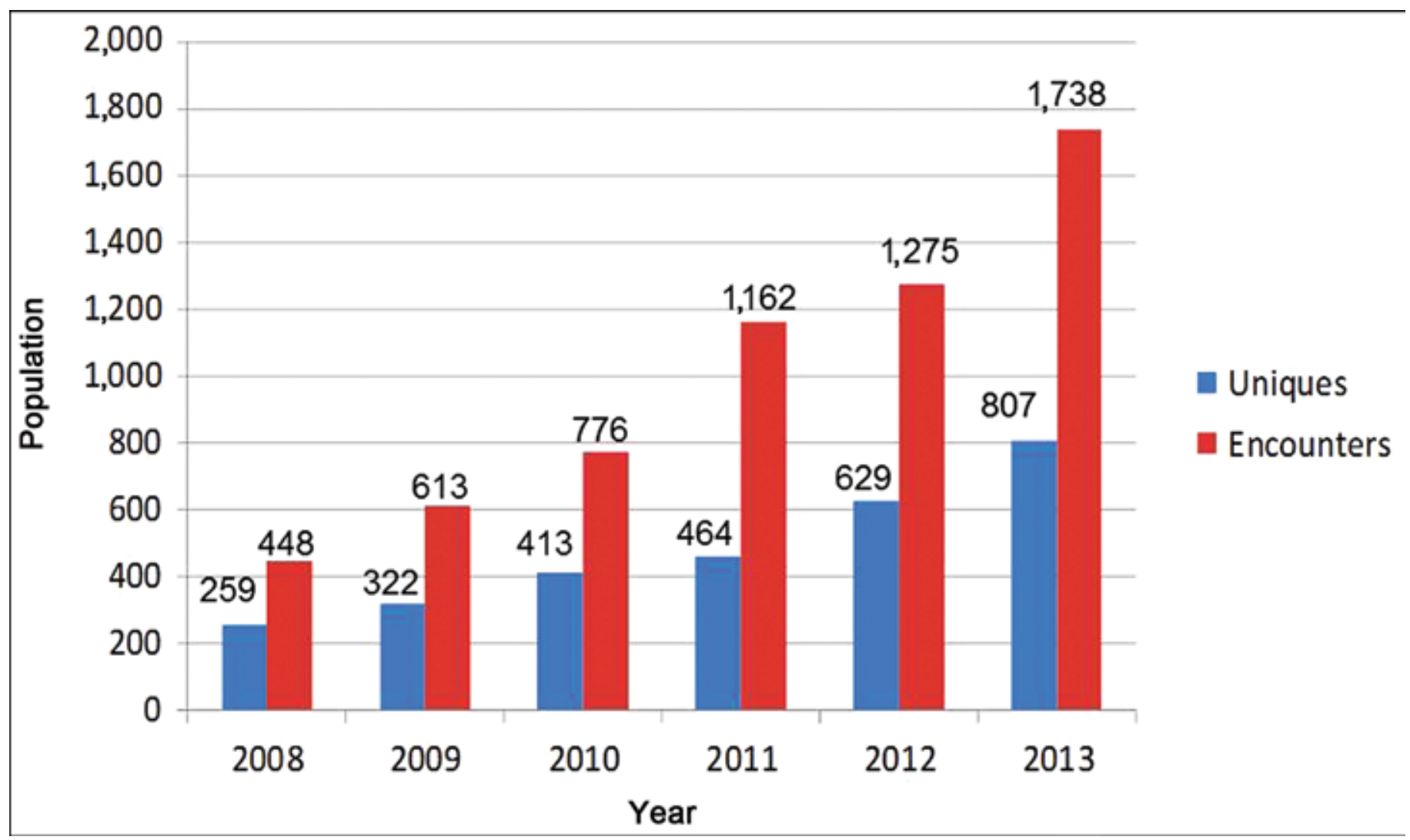

Figure 3.

Outpatient amputee specialty clinic volumes (2008 to 2013). Operation Iraqi Freedom/Operation Enduring Freedom/Operation New Dawn (OIF/OEF/OND) amputee population. Figure shows total number of unique OIF/OEF/OND Veterans with amputations seen in Department of Veterans Affairs amputation specialty clinics as well as total number of clinic encounters for years 2008 to 2013. 
is demonstrated by the fact that, in fiscal year 2013 , 93.8 percent of new patients were seen in an amputation specialty clinic within $14 \mathrm{~d}$ of their desired date. In that same fiscal year, 95.6 percent of established patients were seen in an amputation specialty clinic within $14 \mathrm{~d}$ of their desired date.

\section{Telehealth Amputation Care}

Telehealth Amputation Clinics (TACs) improve access to specialty amputation care for Veterans who live in rural and highly rural areas. Implementation of these TACs has been a key factor in making access to the comprehensive system of amputation care possible. Telehealth services allow larger or more experienced facilities to consult with other facilities to provide specialized amputation care services locally, which reduce the need for Veterans to travel long distances for such care. Many Veterans with amputations have mobility issues, and avoiding the cost and inconvenience of travel is vitally important. Additionally, even for Veterans who have realized a more active lifestyle, frequent travel can affect their employment and/or that of their caregiver. VA has dedicated significant resources into the equipment and training required to perform this service. Figure 4 shows the tremendous growth that has occurred in this program since implementation, including a 46 percent increase in clinical encounters between fiscal year 2012 and fiscal year 2013. Virtual care services have also expanded into telehealth amputee support groups. This has been a great asset to centers where this service would otherwise not be available.

\section{Inpatient Rehabilitation Volumes and UDS-FIM Outcomes}

The majority of rehabilitation services provided to Veterans following amputation take place in the outpatient setting. Because of this, the ASoC has focused primarily on enhancing care excellence in this setting. Many individuals who undergo amputation still require inpatient rehabilitation services, and there is a growing body of evidence supporting the benefits of comprehensive inpatient rehabilitation programs for this population [8-9]. Monitoring these inpatient rehabilitation outcomes is integral to the ASoC. Table 1 displays the volume of VA inpatient rehabilitation admissions and discharges for Veterans with amputations from 2008 to 2013. Table 1 also displays the Uniform Data System Functional Independence Measure outcomes for this
Table 1.

Department of Veterans Affairs inpatient rehabilitation unit amputation patient volumes and Uniform Data System Functional Independence Measure (FIM) outcomes from 2008 to 2013.

\begin{tabular}{lrrrrrr}
\hline Measure & 2008 & 2009 & 2010 & 2011 & 2012 & 2013 \\
\hline $\begin{array}{l}\text { Number of } \\
\text { Discharges }\end{array}$ & 278.00 & 395.00 & 379.00 & 415.00 & 391.00 & 374.00 \\
LOS (days) & 21.00 & 19.00 & 18.00 & 18.00 & 20.00 & 20.00 \\
FIM Change & 16.00 & 15.90 & 17.50 & 16.70 & 17.80 & 19.90 \\
LOS Efficiency & 1.22 & 1.26 & 1.24 & 1.38 & 1.46 & 1.33 \\
$\begin{array}{l}\text { Discharge to } \\
\quad \text { Community (\%) }\end{array}$ & 81.00 & 80.00 & 85.00 & 85.00 & 84.00 & 83.00 \\
\hline
\end{tabular}

LOS = length of stay.

population. As demonstrated, volumes and functional outcomes for Veterans with amputations treated in the inpatient rehabilitation setting have remained stable or improved over the time period. Of note is the improvement in FIM efficiency and an average rate of discharges to the community of 83 percent in fiscal year 2013, which is $\mathbf{8}$ percent greater than the average national private sector rate of 75 percent.

\section{Patient Satisfaction}

Patient satisfaction is an important performance outcome because it provides a general reflection of program quality and the patient-centric nature of the services provided [10]. Patient satisfaction in the outpatient clinic setting is currently obtained at the individual medical facility level. In 2013, the VA implemented a national patient satisfaction tool, the Universal Stakeholder Participation and Experience Questionnaire, for collecting data on patients admitted to a VA inpatient rehabilitation setting. Table 2 provides the spectrum of satisfaction outcomes assessed with this tool. This table shows overall very high satisfaction ratings for patients admitted to VA inpatient rehabilitation settings and that the satisfaction level of Veterans with amputations is comparable or slightly better than this overall level.

\section{ADDITIONAL PROGRAM ACTIVITIES AND ACCOMPLISHMENTS}

\section{CARF Amputation Specialty Accreditation}

The Commission for Accreditation of Rehabilitation Facilities (CARF) is an independent, nonprofit 


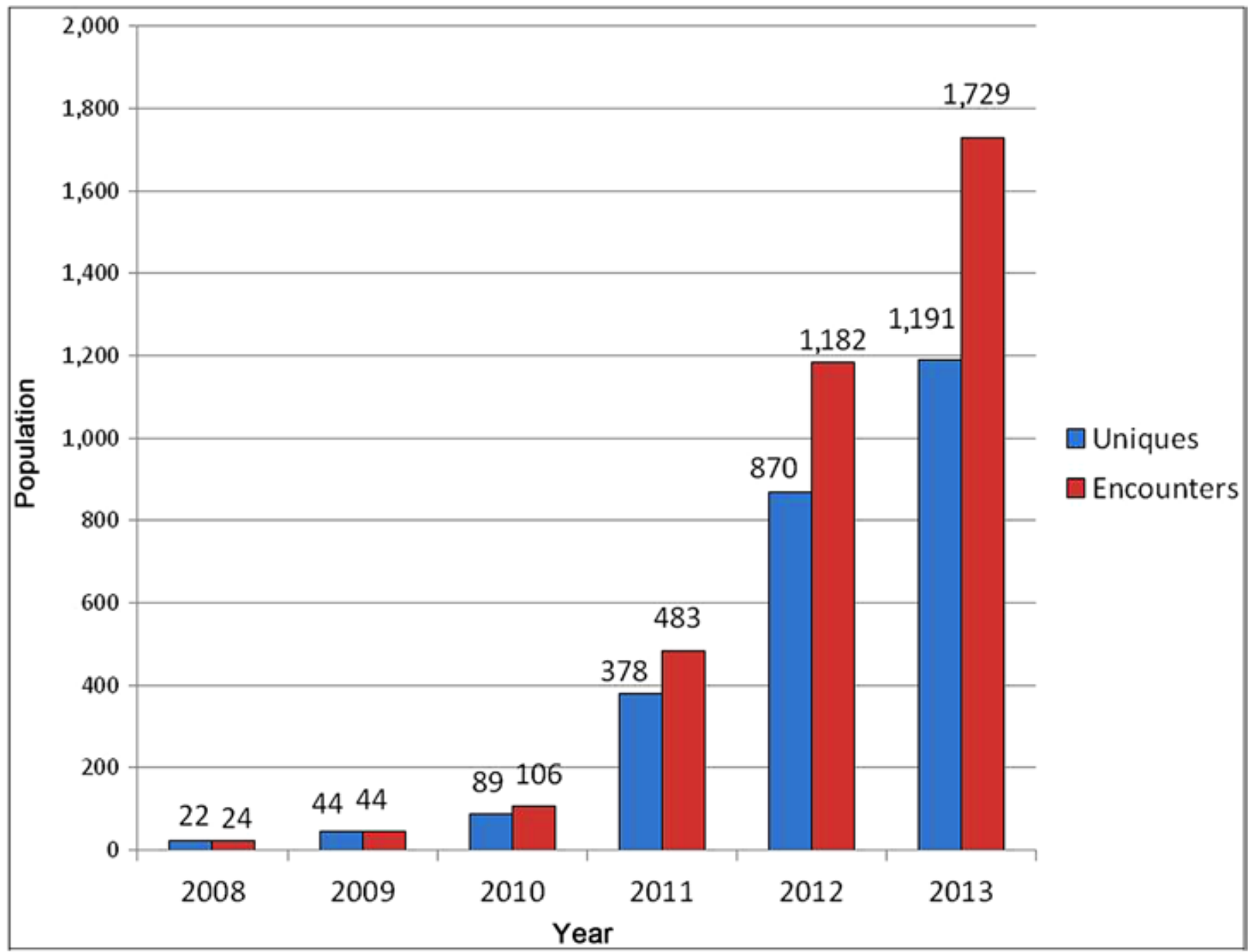

\section{Figure 4.}

Telehealth amputee specialty clinic volumes (2008 to 2013). Figure shows total number of unique Veterans with amputations seen in Department of Veterans Affairs amputation telehealth clinics as well as total number of telehealth clinic encounters for years 2008 to 2013.

organization that serves as the premier accrediting body for rehabilitation programs worldwide. CARF accreditation signals a service provider's commitment to continually improving services, encouraging feedback, and serving the community. CARF first offered specialty accreditation in amputation care in 2008. One of the goals for the ASoC from the early implementation period has been for each of the RAC and PANS medical facilities to obtain CARF Amputation Specialty Accreditation. Of the original RAC and PANS facilities, 95 percent (21 of 22 locations) have achieved this designation. This accreditation status signifies that each of these facilities has obtained a distinguished level of expertise and provides a comprehensive spectrum of services for Veterans with amputations. It is also significant that, of the rehabilitation programs worldwide that have currently achieved CARF Amputation Specialty accreditation, 35 percent (21 of 60 programs) are VA medical centers.

\section{Education and Training}

Education and training are the primary mechanisms that the ASoC has used to enhance the value and uniformity of amputation care across the VA. This education and training has been focused toward rehabilitation providers, including PM\&R physicians, prosthetists, physical therapists, and occupational 
therapists, and has taken various forms. The ASoC has sponsored six large, face-to-face conferences and seven regional conferences since 2008. Most of these conferences were held in collaboration with the DOD and have included attendees and presenters from the DOD's military treatment facilities. This education and training has also included Web-based education and online training programs. In 2011, the ASoC, in conjunction with VA's Prosthetic and Orthotic Services, developed and published an Amputee Clinic Web Course for VA clinical providers. Additionally, as new prosthetic components with advanced technology have become commercially available, such as the Ottobock Genium and X2 prosthetic knees (Ottobock; Duderstadt, Germany), the VA has supported clinical providers and clinical teams to obtain the required certification training in order to prescribe and fit these components.

The ASoC has also collaborated with the DOD on the development of clinical practice guidelines (CPGs) in the area of amputation care. These CPGs are designed to support state-of-the-art practice in the care of patients with amputations by incorporating the most recent medical evidence into practice recommendations. They are designed to provide information and assist decision-making. The CPG for the Rehabilitation of Lower Limb Amputation (http://www.healthquality. va.gov/guidelines/rehab/amp/index.asp), published in 2009 , includes a clinician toolkit describing strategies for pain management and the assessment of gait deviations following lower-limb amputation. Approval for the Upper Extremity Amputation Rehabilitation CPG was obtained in October 2012, and this guideline is expected to be published in the summer of 2014 .

The ASoC has worked to ensure that VA has an adequate supply of well-trained $P M \& R$ physicians to care for the growing Veteran amputee population by establishing amputation care fellowship training programs, with funding provided by the VA Office of Academic Affiliations. These fellowship programs have been initiated at two of the VA RACs, and there is the potential to expand these training opportunities in the future. The first fellow to complete the year-long training was retained to continue working at the VA after completing her fellowship.

\section{ASoC Handbook}

The ASoC Handbook was developed and published in $\mathbf{2 0 1 2}$ for the purpose of defining policy regarding
Table 2.

Patient satisfaction outcomes (Universal Stakeholder Participation and Experience Questionnaire [USPEQ] data for Veterans admitted to Department of Veterans Affairs [VA] inpatient rehabilitation units). Table compares satisfaction outcomes data of Veterans with amputations with overall population of Veterans admitted to VA inpatient rehabilitation units.

\begin{tabular}{ccc}
\hline uSPEQ Data & Amputation \\
(July-September 2013) & $(n=48)$ & $\begin{array}{c}\text { Overall VA } \\
(n=4,611)\end{array}$ \\
\hline
\end{tabular}

Service Responsiveness

Service times OK with me

Got what I needed, when I needed it

100.0

96.0

Enough staff to meet needs

100.0

93.1

Informed Choice

Staff made accommodations

100.0

94.9

Opportunity to make important

100.0

95.1 choices

I agreed with goals in my plan

100.0

96.0

Respect

Respected as a person

100.0

97.3

Staff respected privacy

95.8

96.2

Participation

Able to deal with everyday

97.9

87.8

activities

Able to make important choices

97.9

94.4

Able to do needed things without

93.8

85.8 barriers

\section{Overall Value}

Would recommend to friend

95.7

96.8

Services met my expectations

95.7

94.5

Services enabled me to do things

100.0

94.3 better

Met my need

100.0

95.4

Note: Data given as percentage answering "strongly agree" or "agree."

the provision of care within the ASoC. The handbook describes the scope and procedures for the provision of these interdisciplinary specialized services and provides guidance to the field and VA leadership for program development and sustainment. The handbook describes the integrated care system that provides specialized expertise in amputation rehabilitation. 
The new VA policies and procedures described in the handbook reflect innovations and efforts to systematize the provision of rehabilitative care for Veterans with amputations.

\section{Patient Education}

In addition to education and training for VA clinical providers, the $\mathrm{ASoC}$ has also been dedicated to providing education to Veterans and their families. This Veteran-centered education has included the development of a comprehensive patient manual, "The Next Step: The Rehabilitation Journey after Lower Limb Amputation." This extensive resource provides Veterans and their families with information regarding managing life after amputation, from before surgery through lifelong follow-up. In addition, the VA ASoC has developed and made available amputation content for the Veterans Health Library, which is an online resource for Veterans (http://www.veteranshealthlibrary.org/). Through the Veterans Health Library's partnership with a nonprofit corporation, Amputee Coalition, Veterans also have access to a large volume of patient education resources that have been developed (http://www. amputee-coalition.org/).

\section{Peer Support Programs}

Limb amputation affects not only the Veteran but also his or her support systems. In order to address this issue, the VA ASoC has partnered with the Amputee Coalition to establish peer support programs as part of the ASoC. The peer support programs include direct one-on-one peer support and the development of peer support groups. VA personnel have achieved certification through the Amputee Coalition to train peer supports. These certified trainers have trained and certified Veterans with amputations across the country to be peer supporters for fellow Veterans with amputations. In addition, the VA has implemented the Amputee Coalition's Promoting Amputee Life Skills program at many of its RAC and PANS locations.

\section{Amputee Data Repository}

The Amputee Data Repository was part of original conceptualization for the ASoC. The development process was formally initiated in 2010 , with the development and publication of both an Amputee Data Repository guidance document and a VA Information Technology Business Development Plan proposal. In the spring of 2012, the Veterans Health Administra- tion Support Service Center established financial and technical support for the development of the project. The overall goals of the repository are to provide a data system for the ASoC to observe care volumes and patterns, to understand variations in treatment, to examine factors that influence prognosis and outcomes, to assess effectiveness of care strategies, and to influence clinical practice through data analysis. The first phase of the project, which includes the identification and description of the Veteran population with limb amputation, is nearing completion. The variables described include general demographics, comorbid medical conditions, amputation characteristics, and clinical encounters. Using strict criteria, a very thorough review has been completed to determine the most appropriate outcome measures for the ASoC to implement clinically and to track through the repository. These outcome measures span a wide spectrum of domains, from functional mobility and independence to prosthetic satisfaction and overall quality of life. The next phase of the repository will be the collection and analysis of these data prospectively in the clinical setting in a systematic fashion. Once fully implemented, the Amputee Data Repository will be a valuable tool for clinicians as well as a great resource for future research initiatives. Clinicians and researchers will have access to the amputee database under a formal approval process. Reporting from the database will also include readily available briefing books that summarize key results and trends. Regularly generated reports and dashboard summaries will be available for ASoC providers and leadership.

\section{Extremity Trauma and Amputation Center of Excellence}

The Extremity Trauma and Amputation Center of Excellence (EACE) is a joint VA-DOD center established in 2011 to facilitate continuous care and research related to traumatic limb injuries and amputations across the DOD and VA healthcare networks. The objectives of the EACE include the implementation of a comprehensive plan and strategy spanning both the DOD and the VA for the mitigation, treatment, and rehabilitation of traumatic limb injuries and amputations. The EACE also provides coordination, oversight, and support for limb trauma and amputation research initiatives. This research encompasses scientific information aimed at saving injured limbs, avoiding amputations, and preserving and restoring the function of injured 
limbs. This research addresses military medical needs and includes the full range of scientific inquiry from basic science research to translational and clinical research. A great deal of research work has already been accomplished by the center, and a refactoring of the DOD-EACE amputee registry has also been completed.

\section{FUTURE CONSIDERATIONS}

Great advances have occurred over the past $20 \mathrm{yr}$ in the areas of prosthetic technology and amputation rehabilitation. These advances include the development of artificial limb components with sophisticated microprocessor control and active power systems, virtual reality rehabilitation training environments, and surgical techniques to provide more intuitive and physiologic control of prosthetic arms. While these developments have improved functional outcomes and quality of life for Veterans with amputations, they have also created new challenges for rehabilitation providers in that the appropriate application of these advances requires highly specialized knowledge and skills [11]. For the ASoC to continue to provide the highest quality care to Veterans with amputations in the future, clinical providers must maintain the most up-to-date training and clinical experience with new technology and procedures. This challenge will be ongoing with new developments in regenerative medicine, transplant immunology, limb salvage techniques, robotics, and brain-computer interfaces on the horizon because these advances have the potential to further revolutionize the care of Veterans with amputations.

\section{SUMMARY}

From 2008 to 2013, the VA ASoC has evolved from a conceptual model to a fully operational healthcare delivery system for Veterans with limb amputations. With this development, the ASoC has been able to meet both the needs of the growing Veteran population with dysvascular amputations and the specialized needs of Veterans and servicemembers who have sustained complex, combat-related amputations in recent military conflicts. In addition, through extensive training, innovative program development, and the establishment of collaborative partnerships, the VA ASoC has been able to achieve its goal to enhance the environment of care and ensure consistency in the delivery of rehabilitation services for Veterans with amputations. With these accomplishments, the ASoC is well positioned to fulfill its vision to be a world leader in lifelong amputation care.

\section{ACKNOWLEDGMENTS}

\section{Author Contributions:}

Study concept and design: J. B. Webster, D. X. Cifu,

C. E. Poorman.

Acquisition of data: J. B. Webster, C. E. Poorman.

Drafting of manuscript: J. B. Webster.

Critical revision of manuscript for important intellectual content: J. B. Webster, D. X. Cifu, C. E. Poorman.

Disclaimer: The views expressed in this article are those of the authors and do not necessarily reflect the position or the policy of the VA.

\section{Joseph B. Webster, MD;1-2* Cindy E. Poorman, MSPT; ${ }^{2}$ David X. Cifu, MD ${ }^{1-2}$}

${ }^{1}$ Hunter Holmes McGuire VA Medical Center and Department of PM\&R, Virginia Commonwealth University, Richmond, VA; ${ }^{2}$ VA PM\&R National Program Office, Washington, DC

*Email: joseph.webster@va.gov

\section{REFERENCES}

1. Amputation system of care handbook. Washington (DC): VHA; 2012 Aug 15. VHA handbook 1172.03. Available from: http://vaww.va.gov/vhapublications/publications. cfm?Pub=2

2. Prevention of Amputation in Veterans Everywhere (PAVE) program directive. Washington (DC): VHA; 2013 Aug 20. VHA directive 2012-020. Available from: http://vaww.va.gov/vhapublications/ViewPublication. asp?pub ID $=2778$

3. Sigford BJ. Paradigm shift for VA amputation care. J Rehabil Res Dev. 2010;47(4):xv-xix. [PMID:20803396] http://dx.doi.org/10.1682/JRRD.2009.02.0020

4. Fletcher DD, Andrews KL, Hallett JW Jr, Butters MA, Rowland CM, Jacobsen SJ. Trends in rehabilitation after amputation for geriatric patients with vascular disease: Implications for future health resource allocation. Arch Phys Med Rehabil. 2002;83(10):1389-93. 


\section{[PMID:12370874]}

http://dx.doi.org/10.1053/apmr.2002.34605

5. Dillingham TR, Pezzin LE, MacKenzie EJ. Limb amputation and limb deficiency: Epidemiology and recent trends in the United States. South Med J. 2002;95(8): 875-83. [PMID:12190225]

6. VA amputee data repository. Washington (DC): VHA Support Service Center. [cited 2014 Feb 18].

7. Department of Veterans Affairs Office of the Inspector General. Health care inspection: Prosthetic limb care in VA facilities. Washington (DC): VA Office of Inspector General; 2012 Mar 8. Report No. 11-02138-116. Available from: http://www.va.gov/oig/pubs/VAOIG11-02138-116.pdf

8. Stineman MG, Kwong PL, Xie D, Kurichi JE, Ripley DC, Brooks DM, Bidelspach DE, Bates BE. Prognostic differences for functional recovery after major lower limb amputation: Effects of the timing and type of inpatient rehabilitation services in the Veterans Health Administration. PM R. 2010;2(4):232-43. [PMID:20430324] http://dx.doi.org/10.1016/j.pmrj.2010.01.012

9. Kurichi JE, Ripley DC, Xie D, Kwong PL, Bates BE, Stineman MG. Factors associated with home discharge after rehabilitation among male veterans with lower extremity
amputation.PMR. 2013;5(5):408-17.[PMID:23159239]

http://dx.doi.org/10.1016/j.pmrj.2012.09.578

10. Al-Abri R, Al-Balushi A. Patient satisfaction survey as a tool towards quality improvement. Oman Med J. 2014; 29(1):3-7. [PMID:24501659] http://dx.doi.org/10.5001/omj.2014.02

11. Resnik L, Meucci MR, Lieberman-Klinger S, Fantini C, Kelty DL, Disla R, Sasson N. Advanced upper limb prosthetic devices: Implications for upper limb prosthetic rehabilitation. Arch Phys Med Rehabil. 2012;93(4):710-17. [PMID:22464092]

http://dx.doi.org/10.1016/j.apmr.2011.11.010

This article and any supplementary material should be cited as follows:

Webster JB, Poorman CE, Cifu DX. Department of Veterans Affairs Amputation System of Care: 5 years of accomplishments and outcomes. J Rehabil Res Dev. 2014;51(4):vii-xvi. http://dx.doi.org/10.1682/JRRD.2014.01.0025 